\title{
An interpretation of irregular dyke forms in the Itivdleq shear zone, West Greenland
}

\section{David Nash}

\section{Introduction}

Around the settlement of Itivdleq the general form of the Kangâmiut dykes varies according to whether the intrusions occur within or outside the pre-dyke Itivdleq shear zone (fig. 1; Nash, this volume). Outlined below is an interpretation of the origin and development of the different dyke forms in the shear zone and some brief remarks on the significance of the results.

\section{Field relations}

Outside the Itivdleq shear zone the dykes, which trend NE to NNE, exhibit a planar parallel-sided form with large length-width ratios; their geometry reflects the configuration of the syn-magmatic fracture system into which they were emplaced. Primary igneous textures are extensively preserved in the intrusions although many show signs of minor intra-dyke deformation. However only in the large, multiple intrusions (commonly exceeding $60 \mathrm{~m}$ in width) are the effects of this deformation developed to any great extent.

Within the shear zone differences occur, not only in the shape, but also in the trend and tectonic state of the Kangâmiut dykes. The majority of the dykes show irregular, primary shapes (e.g. non-tabular) with curvilinear outlines and highly variable length-width ratios in both horizontal and vertical sections (fig. 2). A pinch and swell form broadly represents the most commonly occurring dyke shape, although this term encompasses a wide variety of forms ranging from intrusions composed of short, lemon-shaped swells (which produces in three dimensions an egg-box like form with rounded edges) to others with elongated, spearlike swells interconnected by narrow (less than $10 \mathrm{~cm}$ ) intrusive necks. In certain cases the interconnecting necks are absent and the isolated swells form, what are referred to here as pod intrusions. Significantly, a group of pods, which in some cases are compositionally distinct, will be with their long axes along a common line that trends in the same direction as the various pinch and swell forms. The pods would appear, therefore, to represent, at the present level of erosion, unconnected parts of a single intrusion (fig. 2).

In the shear zone all the Kangâmiut dykes trend E to ENE, that is subparallel to the pre-existing shear zone fabrics. On close inspection it is found that the intrusions locally deform the host rocks producing a strong structural concordance between the outline of the weakly deformed dyke and the strongly foliated gneiss. In thin section the deformation of the host rock is expressed as a strong recrystallisation of the amphibolite facies assemblage.

With a few notable exceptions all the dykes within the shear zone have suffered some 


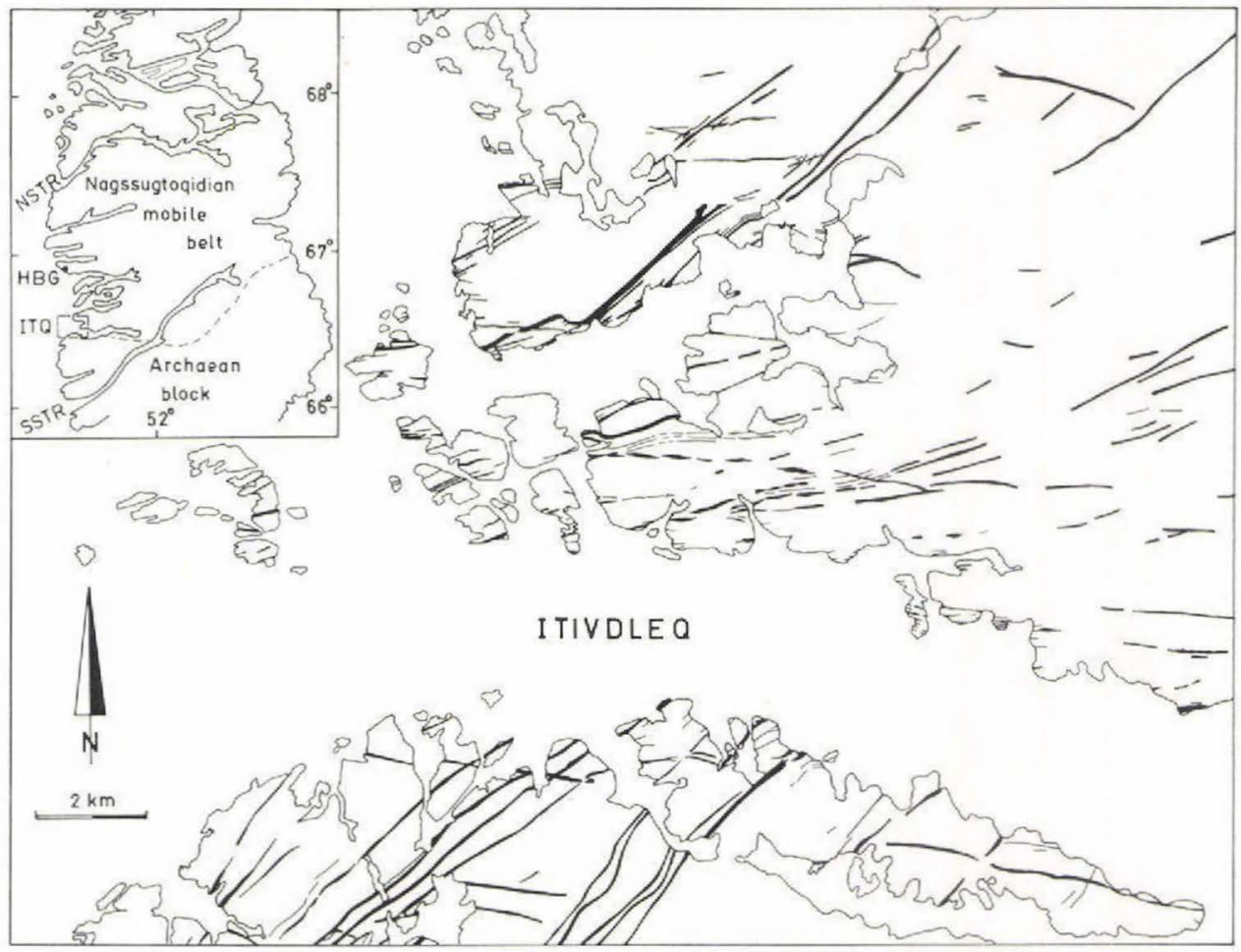

Fig. 1. Distribution and orientation of Kangâmiut dykes in the western part of Itivdleq fjord. NSTR Nordre Strømfjord, HвG Holsteinsborg, ITQ Itivdleq, sSTR Søndre Strømfjord.

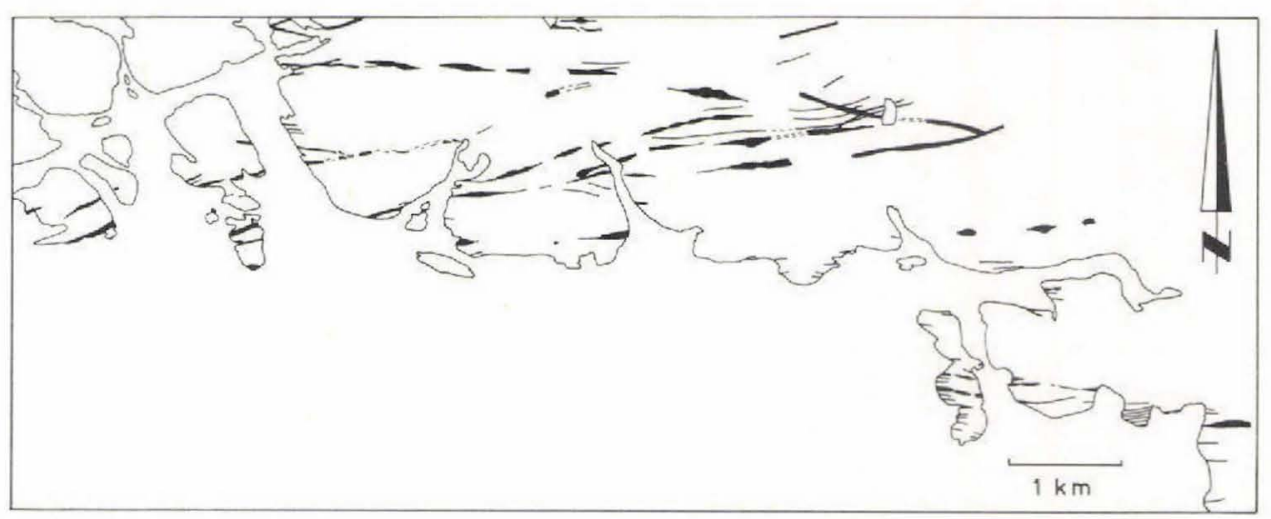

Fig. 2. Details of Kangâmiut dykes in the central zone of the Itivdleq shear zone. 


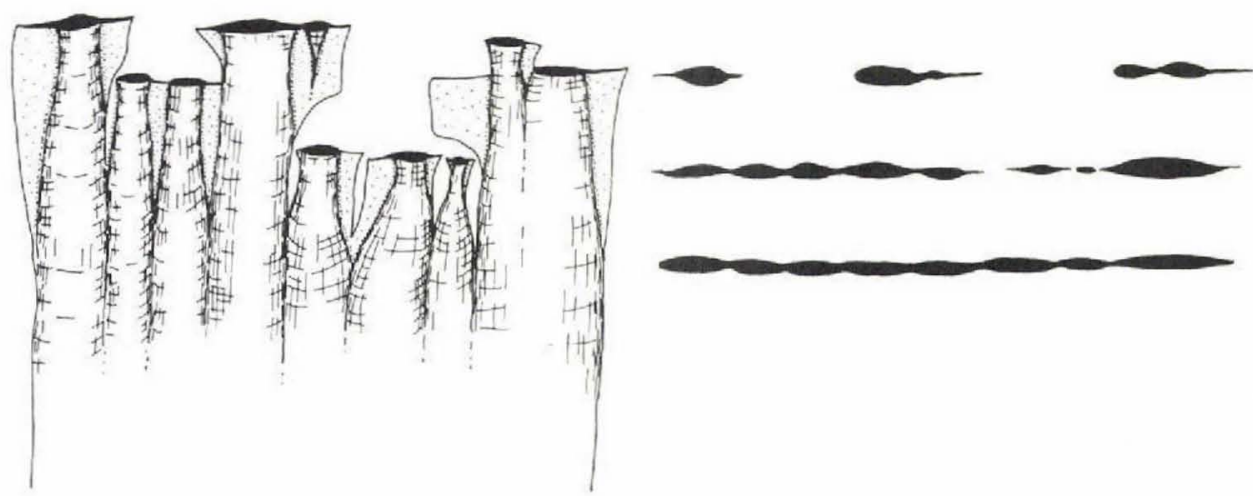

Fig. 3. Idealised three-dimensional form of basic dykes. The right side of the figure shows outcrop patterns at the three levels indicated.

degree of ductile deformation. In general the intensity of the deformation is rather low; the tectonite fabric (a margin parallel fabric) is only weakly developed and most intrusions retain large areas with a well-preserved, primary igneous texture. Nevertheless the minor phase of pervasive deformation, which the fabric reflects, must be accounted for in any comprehensive interpretation of the dyke forms.

\section{Interpretation}

Structural and petrographic observations show that, at the time of dyke emplacement, the Itivdleq area was undergoing high-grade metamorphism and experiencing compressional movements related to $\sigma_{1}$ orientated virtually normal to the shear zone (Nash, this volume, fig. 3). Rheologically the area was markedly anisotropic, the granulite facies areas forming rigid blocks which bound the foliated and highly ductile shear zone gneisses.

It is proposed that during dyke emplacement the orientation of the regional stress field greatly inhibited the intrusion of basic magma into the shear zone. The surprising paucity of intrusions in some of the most intensely deformed areas (pre-dyke) is considered to reflect this fact. Only at times when the regional stresses temporarily relaxed was magma capable of intruding the shear zone $\left(\mathrm{P}_{\text {magma }}>\mathrm{P}_{\text {tectonic }}\right)$. Similarly, it was only at these times that the strong structural anisotropy of the shear zone fabrics was able to exert any major influence on the distribution and orientation of the Kangâmiut dykes. The dykes were consequently intruded sub-parallel to the pre-existing shear fabrics.

\section{Interpreted three-dimensional form}

The three-dimensional form of the dykes intruding the shear zone is considered to resemble that of an upward-pointing hand (fig. 3). The upper part of this basic intrusive form consists of a series of fingers (pods in two dimensions) which, lower down, may become linked by interconnecting necks (pinch and swell-type forms). At depth the individual parts 


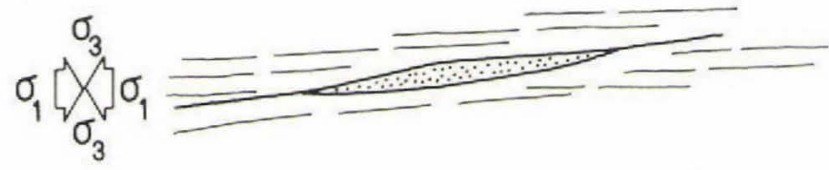

1

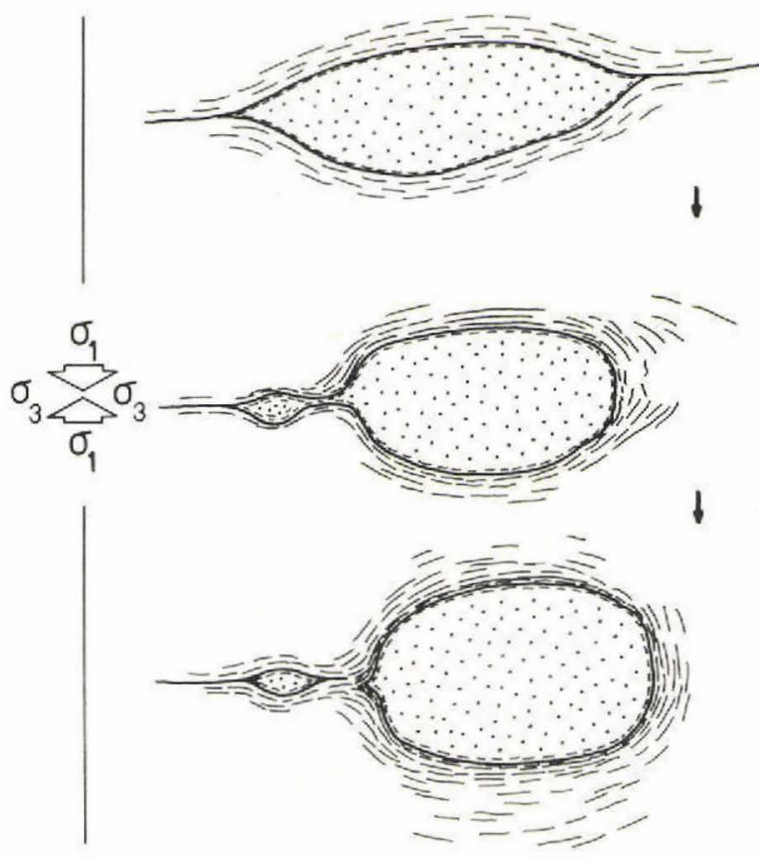

Fig. 4. Interpreted - syn-magmatic shape changes of pod intrusion. See text for explanation.

of the intrusion unite to form a single sheet (planar parallel-sided forms). The major dyke forms in the shear zone therefore represent sections at different levels throughout the same basic form. Upwards propagation of this form was only maintained in the environment of a relaxed stress field. With reapplication of the regional stresses ( $\left.P_{\text {tectonic }} \geq P_{\text {magma }}\right)$ the shear zone would become an unsuitable site for further intrusion and once again, magma would solely intrude the granulite-facies areas.

\section{Syn-magmatic shape changes}

At this point the 'arrested' intrusions, which are still in a largely molten state, begin to suffer syn-magmatic shape changes. Undeformed pod intrusions (fig. 4), for example, enhibit in situ horizontal swelling which intensely deforms the host rocks and produces a range of genetically related swell shapes. East-west elongated pods (initial intrusive two-dimensional shape) shorten along, and swell normal to, their long axes to form sub-rounded, ball-shaped 


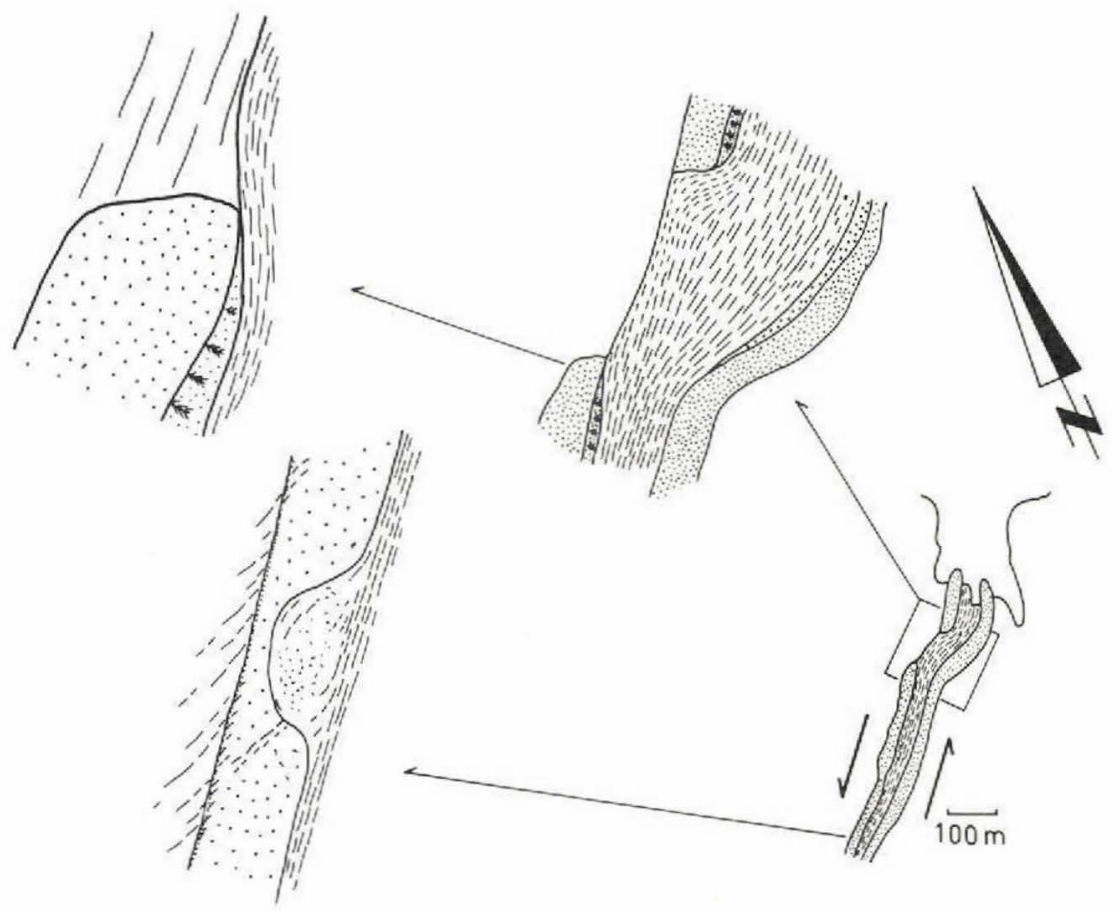

Fig. 5. Syn-magmatic features of multiple intrusion.

swells. This sequence of changes would only develop however when the volume of magma passing through the fissure increased. Temporary volume increases may occur as the magma, already intruded into the shear zone, is tectonically 'squeezed' upward. However, the ultimate modification to the original shape of the pod (e.g. the formation of N-S elongated swells horizontally propagating in the direction of $\sigma_{1}$ ) is probably never achieved since the main supply of magma (e.g. from the parent magma chamber underlying the dyke swarm) is cut-off by the effects of increasing normal stress across the shear zone.

More dramatic results of syn-magmatic tectonic 'squeezing' in the shear zone are observed in the large multiple intrusions (width $60 \mathrm{~m}$ plus, fig. 5). These include syn-magmatic shape distortions (which result in auto-injection from the molten centre of the intrusion), entrainment of consolidated wall rocks and filter pressing.

\section{Syn-consolidation shape changes}

As the dykes were cooled, under compression, two further shape modifications occurred which finally produced the present day form. The sequence of events are interpreted as follows.

At a certain point, prior to final cooling, the viscosity of the dyke would begin to gradually exceed that of the silicic host rocks. Consequently the intrusions, which despite syn-mag- 

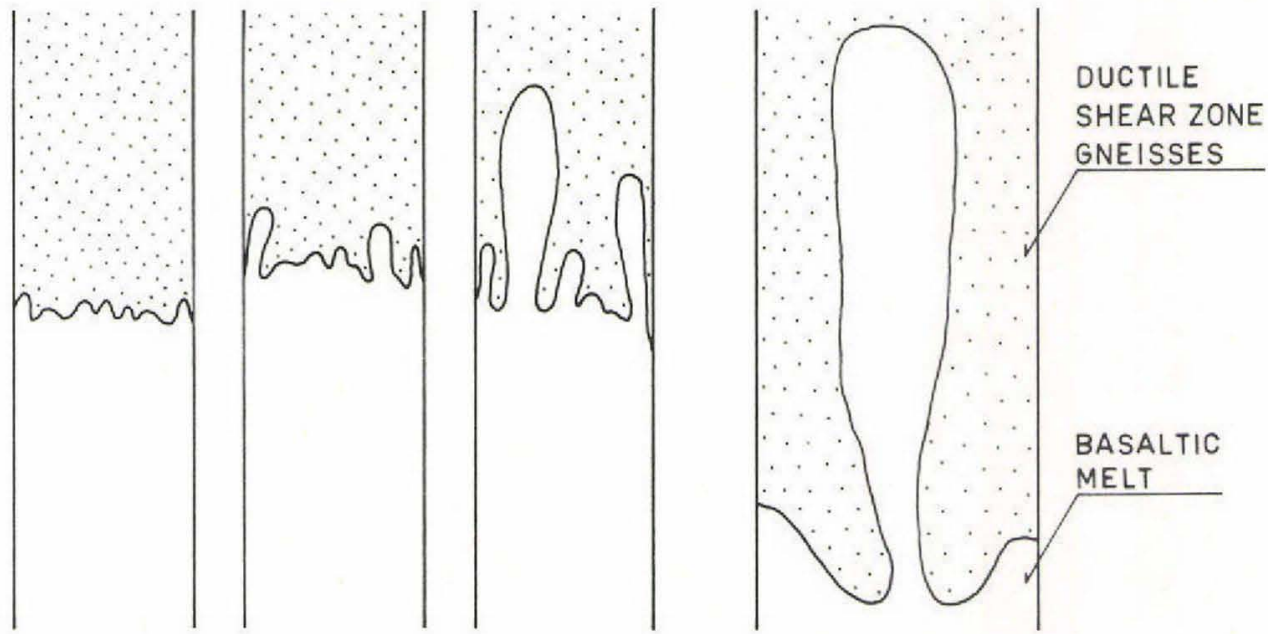

Fig. 6. Application of Saffman \& Taylor's fluid instability model to the problem of Kangâmiut dyke intrusion. A liquid of low viscosity (blank) is forced into an upper medium of higher viscosity (stippled). At a certain velocity of the upward moving interface it becomes unstable and the lower liquid forms elongate fingers which intrude and displace the upper medium.

matic shape changes are still, essentially, elongated east-west (i.e. normal to $\sigma_{1}$ ) begin to tectonically extend. As a result many primary irregularities (i.e. swell terminations and necks) are tectonically 'tightened'. However this extensional phase is short-lived, since in the environment of the shear zone deformation is invariably accompanied by hydration which rapidly cools the dyke. At this lower temperature (with a considerably higher competency contrast between the dyke and gneiss) the style of deformation changes to one of discrete shearing. Minor transverse shears develop across the dyke introducing an angular element to the otherwise rounded contacts. Significantly the shears are wholly confined to dykes; the neighbouring gneiss deforms ductily in order to accomodate the distorted contacts. The shears, which form a conjugate set with an acute bisectrix sub-parallel to $\sigma_{1}$, represent the final modification to the shape of the dykes in the shear zone.

\section{Discussion}

An essential part of the interpretation is the suggestion that the upper, intruding end of the intrusion more resembles a row of fingers than a sharp-edged, Andersonian-type wedge (Anderson, 1951).

The origin of this basic intrusive form may be somewhat similar to that of finger instabilities which develop between two viscous fluids accelerated in a direction normal to the interface (Saffman \& Taylor, 1958; Elder, 1970). The intersection of the Itivdleq shear zone with the main basaltic underplate supplying the Kangâmiut dyke swarm may be broadly compared to the interface between two media of different viscosities in Saffman \& Taylor's experiments (fig. 6). In the case of the dykes in Itivdleq the triggering mechanism, which 
allowed intrusion to commence, was the reduction in normal stress across the shear zone. This is equivalent, in the case of the model, to effectively increasing the permeability of the upper medium.

The wide variety of irregular dyke forms in the Itivdleq shear zone are considered to have developed in the relatively short time period between initial emplacement and final consolidation. In the light of this interpretation it is worth considering how the structural history of the Itivdleq area might have been reconstructed had (a) the area been affected by strong post-dyke (Nag. 2) deformation or (b) if only aerial photograph and brief reconnaissance studies of the area had been made. In either case it is likely that the change in orientation, structural state, and form of the intrusion on entering the shear zone would have been interpreted in terms of a major phase of post-dyke deformation.

As a final point it follows from the interpretation that pod intrusions may, elsewhere, be good indicators of syn-metamorphic, and possibly syn-tectonic dyke emplacement. The interpretation also poses a more controversial question as to whether tectonic pinch and swell may also largely originate in the same environment.

\section{References}

Anderson, E. M. 1951: The dynamics of faulting and dyke formation. Edinburgh: Oliver \& Boyd, 206 pp.

Elder, J. W. 1970: Quantitative laboratory studies of dynamic models of igneous intrusions. In Newall, G. \& Rast, N. (edit.) Mechanism of igneous intrusion. Geol. J. Spec. Issue 2, 245-260.

Nash, D. 1979: Nagssugtoqidian tectonics at the western end of the Itivdleq shear zone, West Greenland. Rapp. Gronlands geol. Unders. 89 (this volume).

Saffman, P. G. \& Taylor, G. 1958: The penetration of a fluid into a porous medium or Hele-Shaw cell containing a more viscous liquid. Phil. Trans. R. Soc. Lond. A, 245, 312-329.

King Homes,

1-8-10, Kami-Meguro,

Meguro-Ku,

Tokyo 153,

Japan. 